Ambiente \& Água - An Interdisciplinary Journal of Applied Science
ISSN 1980-993X - doi:10.4136/1980-993X
www.ambi-agua.net
E-mail: ambi-agua@agro.unitau.br

\title{
Relação entre vazão e qualidade da água em uma seção de rio
}

\author{
doi: 10.4136/ambi-agua.1278
}

Received: 15 Jan. 2014; Accepted: 08 Mar. 2014

\author{
Luciano Vieira Barreto ${ }^{1}$; Micael de Souza Fraga ${ }^{2 *}$; Flávia Mariani Barros ${ }^{1}$; \\ Felizardo Adenilson Rocha ${ }^{3}$; Jhones da Silva Amorim ${ }^{1}$; \\ Stênio Rocha de Carvalho"; Paulo Bonomo ${ }^{1}$; Danilo Paulúcio da Silva ${ }^{1}$ \\ ${ }^{1}$ Universidade Estadual do Sudoeste da Bahia (UESB).- Itapetinga, BA, Brasil \\ ${ }^{2}$ Universidade Federal de Viçosa (UFV) - Viçosa, MG, Brasil \\ Departamento de Engenharia Agrícola \\ ${ }^{3}$ Instituto Federal da Bahia (IFBA) - Vitória da Conquista, BA, Brasil \\ *Autor correspondente: e-mail: micaelfraga @ yahoo.com.br, \\ lucianoengenheiroambiental@yahoo.com.br, mariamariani@yahoo.com.br, \\ felizardoar@hotmail.com, jhones_sa@hotmail.com, steniophn@ hotmail.com, \\ bonomopaulo@gmail.com, danilopaulucio@gmail.com
}

\section{RESUMO}

O objetivo do presente trabalho foi avaliar a dinâmica de determinadas variáveis de qualidade da água em função da vazão, em uma seção transversal do rio Catolé Grande próxima ao ponto de captação de água para abastecimento do município de Itapetinga-BA. Amostras de água foram coletadas por integração vertical, em diferentes meses, correspondente a diferentes vazões. Nessas amostras foram realizadas análises de potencial hidrogeniônico $(\mathrm{pH})$, turbidez, sólidos totais dissolvidos, salinidade e fósforo total. A velocidade do fluxo foi medida com o auxílio do molinete e a vazão foi calculada pelo produto da velocidade pela área da seção. Os resultados apontaram que a salinidade, os sólidos totais dissolvidos e a turbidez apresentaram comportamentos semelhantes, aumentando linearmente com o incremento da vazão, enquanto o $\mathrm{pH}$ apresentou tendência contrária. As concentrações de fósforo apresentaram comportamento exponencial em função da vazão, sendo que os valores médios desta variável ultrapassaram os limites estipulados pela resolução CONAMA 357 para a pior classe de qualidade de água doce.

Palavras-chave: monitoramento, poluição hídrica, hidrometria.

\section{Relationship between stream flow and water quality in a river section}

\section{ABSTRACT}

The objective of this study was to evaluate the dynamics of water quality variables in relation to the stream flow rate in a cross section of the Catolé Grande River near the point of water uptake to supply the city of Itapetinga-BA. Water samples were collected by vertical integration in different months, corresponding to different flow rates. This work analyzed the hydrogenionic potential $(\mathrm{pH})$, turbidity, total dissolved solids, salinity and total phosphorus of the water samples. The flow velocity was measured using a flow meter. The flow rate was calculated by the product of velocity by cross section area. The results showed that salinity, 
total dissolved solids and turbidity had similar behaviors in relation to the flow rate, with increased concentrations of these variables with increasing river flow rate, whereas the opposite was observed for $\mathrm{pH}$. Phosphorus concentrations showed an exponential behavior as a function of flow rate, and the average values of this variable exceeded the limits stipulated by CONAMA Resolution 357 for the worst class of freshwater quality.

Keywords: monitoring, water pollution, hydrometric.

\section{INTRODUÇÃO}

O crescimento populacional e as atividades humanas tem se despontado como um dos maiores responsáveis pela poluição do meio aquático. Os rios se tornaram ao longo dos anos depositários de rejeitos e resíduos de diversas formas: os esgotos domésticos e as águas residuárias provenientes de atividades pecuárias contribuem com elevadas cargas orgânicas; as indústrias com uma série de compostos sintéticos e elementos químicos potencialmente tóxicos e as atividades agrícolas com a contaminação por pesticidas e fertilizantes ricos em sais minerais (Fernandes Neto e Ferreira, 2007). Essas ações antrópicas podem afetar a qualidade do ambiente para os organismos aquáticos ou mesmo para a saúde humana.

O conhecimento do estado das águas permite auxiliar na definição de usos pretendidos, avaliar sua qualidade e indicar quais atividades humanas causam ou podem causar sua degradação (Haddad e Magalhães Júnior, 2010). Realizado de forma correta, o monitoramento qualitativo e quantitativo das águas pode indicar quais atividades humanas são potencialmente degradantes a este recurso, constituindo um dos instrumentos mais importantes no controle ambiental.

Conhecer a qualidade da água disponível é fundamental para a gestão dos recursos hídricos, este conhecimento pode ser representado por meio de diversas variáveis de qualidade as quais traduzem suas principais características. Assim, para realizar o controle da poluição das águas de rios e reservatórios, utilizam-se os padrões de qualidade, que definem os limites de concentração a que cada substância presente na água deve atender. Esses padrões dependem da classificação das águas interiores, que é estabelecida segundo seus usos preponderantes, conforme a Resolução do Conselho Nacional do Meio Ambiente (CONAMA) 357/05, variando da Classe especial até a Classe 4.

$\mathrm{O}$ uso de indicadores físico-químicos da qualidade da água consiste no emprego de variáveis que se correlacionam com as alterações ocorridas na bacia, sejam essas de origem antrópica ou natural. Deste modo, percebe-se que os cursos de água de uma bacia hidrográfica são afetados pelo uso e ocupação do solo e por contaminantes despejados nos recursos hídricos de toda a área de drenagem (Braga et al., 2005).

Portanto, o monitoramento dos corpos de água, tanto qualitativo quanto quantitativo, é de suma importância, principalmente para os que são utilizados como meio de abastecimento deste recurso para a população, pois, além de se evitar possíveis agravantes à saúde pública, podem-se promover planos ou projetos que visem à recuperação dos corpos de água já intensamente degradados pelas atividades antrópicas.

Diante do exposto, o presente estudo teve como objetivo verificar a influência de diferentes níveis de vazão no comportamento de variáveis de qualidade de água.

\section{MATERIAL E MÉTODOS}

O local do presente estudo esta situado na bacia hidrográfica do rio Catolé Grande, sendo esta pertencente à bacia do rio Pardo. Esta sub-bacia, considerando o sistema de projeção Universal Transversa de Mercator (UTM), está contida na zona 24, entre os paralelos N: 8380000 - 8226000 e meridianos E: 300000 - 385000, estando integralmente localizada na 
região sudoeste da Bahia. O rio Catolé nasce no planalto de Vitória da Conquista, próximo à cidade de Barra do Choça, dirigindo-se à calha do rio Pardo no sentido Nordeste-Sudeste, com seção de controle a jusante da cidade de Itapetinga-BA.

No que tange às atividades econômicas, as regiões de Itapetinga, Itambé e Caatiba, situadas no médio e baixo Catolé, são ocupadas pela atividade agropastoril extensiva. Já nas localidades de Vitória da Conquista e Barra do Choça, no alto Catolé, a atividade predominante é a produção de café.

A seção transversal do rio Catolé Grande estudada está localizada aproximadamente 50 metros a montante do ponto de coleta de água para abastecimento público do município de Itapetinga, apresentando, em média, largura de 28 metros (para o intervalo de vazões analisados neste estudo).

Para determinação da vazão foi calculada a área da seção transversal do rio a partir do somatório das subseções da seção. A velocidade do curso de água, em cada local de amostragem, foi determinada com o auxílio de um molinete hidrométrico modelo FP211, marca Global Water, e a área da seção transversal por meio de levantamento batimétrico local, segundo metodologia descrita por Pruski et al. (2006). A vazão do curso de água foi obtida pelo produto da velocidade média do escoamento pela área da seção transversal.

As posições horizontais e verticais do molinete para as determinações das velocidades médias foram definidas de acordo com a largura e profundidade do curso de água, conforme metodologia apresentada por Pruski et al. (2006).

Para o perfil transversal em estudo foram definidos três pontos de coleta de amostras de água: lado esquerdo do rio (e), centro do rio (c) e lado direito do rio (d), sendo a distância média dos pontos laterais às suas respectivas margens de $7 \mathrm{~m}$ e do ponto central às margens de $14 \mathrm{~m}$.

As coletas foram realizadas entre janeiro e novembro de 2011, totalizando oito coletas: no verão (07/01/2011 e 11/02/2011), outono (15/04/2011 e 14/05/2011), inverno (10/07/2011 e 20/08/2011) e na primavera (02/10/2011 e 05/11/2011).

As amostragens de água foram realizadas por integração vertical, com o auxilio de um amostrador de sedimentos em suspensão modelo US DH-48, sendo este amostrador aplicado a profundidades de até $2,7 \mathrm{~m}$ e baixas velocidades. As amostras foram acondicionadas em garrafas apropriadas e preservadas segundo metodologia descrita em APHA et al. (2005). Posteriormente foram transportadas diretamente para o Laboratório de Solos da Universidade Estadual do Sudoeste da Bahia, Campus Itapetinga, onde foram efetuadas as análises. Para cada data de amostragem foram realizadas três repetições em cada ponto.

A determinação da turbidez foi realizada pelo método nefolométrico, com o auxílio de um turbidímetro de bancada marca HANNA, modelo HI 93703. A salinidade, o pH e os sólidos totais dissolvidos foram medidos por meio de uma sonda multiparâmetro marca HANNA, modelo OX 9828. O fósforo total foi medido com o auxílio de um fotômetro de bancada, marca HANNA, modelo HI 83208. As análises realizadas por estes equipamentos foram baseadas em APHA et al. (2005).

A partir dos valores das concentrações de cada variável de qualidade de água considerada nesse estudo foram ajustados modelos para avaliação do comportamento dessas variáveis em função das vazões medidas.

Os modelos foram ajustados por meio de análise de regressão, sendo eles escolhidos com base na significância do coeficiente de regressão, no coeficiente de determinação e nas características do fenômeno em estudo. Além disso, também foi realizada a correlação de Pearson entre as variáveis de qualidade de água e a vazão em nível de significância de $1 \%$. Para as análises estatísticas, utilizou-se o software estatístico SAEGED. 


\section{RESULTADOS E DISCUSSÃO}

Os valores de profundidade média, velocidade da água e vazão na seção avaliada do rio Catolé Grande estão apresentados na Tabela 1.

Tabela 1. Valores de profundidade média, velocidade da água e vazão na seção avaliada do rio Catolé Grande em diferentes épocas de coleta.

\begin{tabular}{l|ccc}
\hline Data da coleta & $\begin{array}{c}\text { Profundidade média da seção } \\
(\mathrm{m})\end{array}$ & $\begin{array}{c}\text { Velocidade média } \\
\left(\mathrm{m} \mathrm{s}^{-1}\right)\end{array}$ & $\begin{array}{c}\text { Vazão } \\
\left(\mathrm{m}^{3} \mathrm{~s}^{-1}\right)\end{array}$ \\
\hline $07 / 01 / 2011$ & 1,47 & 0,33 & 8,17 \\
$11 / 02 / 2011$ & 1,52 & 0,15 & 6,47 \\
$15 / 04 / 2011$ & 1,49 & 0,19 & 7,97 \\
$14 / 05 / 2011$ & 1,47 & 0,20 & 8,29 \\
$10 / 07 / 2011$ & 1,40 & 016 & 6,58 \\
$20 / 08 / 2011$ & 1,40 & 0,14 & 5,08 \\
$22 / 10 / 2011$ & 1,41 & 0,13 & 5,58 \\
$05 / 11 / 2011$ & 1,40 & 0,10 & 3,98 \\
\hline
\end{tabular}

De acordo com os dados apresentados na Tabela 1 nota-se que a profundidade média da seção estudada variou entre 1,40 e 1,52 m, a velocidade da água foi menor na coleta realizada em novembro $\left(0,10 \mathrm{~m} \mathrm{~s}^{-1}\right)$, data também em que a vazão foi menor $\left(3,98 \mathrm{~m}^{3} \mathrm{~s}^{-1}\right)$, enquanto a maior velocidade foi verificada na coleta realizada no mês de janeiro $\left(0,33 \mathrm{~m} \mathrm{~s}^{-1}\right)$ cuja vazão foi de $8,17 \mathrm{~m}^{3} \mathrm{~s}^{-1}$.

A seguir são apresentados os comportamentos das variáveis de qualidade de água em função da vazão. Os modelos ajustados neste trabalho são válidos para o rio Catolé Grande, nas vazões entre $3,98 \mathrm{~m}^{3} \mathrm{~s}^{-1}$ e $8,29 \mathrm{~m}^{3} \mathrm{~s}^{-1}$.

\subsection{Potencial Hidrogeniônico (pH)}

$\mathrm{Na}$ Figura 1 estão apresentados os resultados do potencial hidrogeniônico, medidos e estimados por meio de equação ajustada em função das diferentes vazões no rio Catolé Grande.

Nota-se que, houve tendência da diminuição dos valores de $\mathrm{pH}$ com o aumento da vazão, contudo, a amplitude média dos valores observados foi pequena, entre 6,23 e 7,16, indicando valores aceitáveis segundo a Resolução CONAMA n. 357 (Brasil, 2005) a qual estipula valores de $\mathrm{pH}$ entre 6 e 9 para todas as classes de qualidade de água doce, ou seja, Classe 1, que pressupõe os usos mais nobres até a Classe 4 que pressupõe os usos menos nobres.

A pequena variação dos valores de $\mathrm{pH}$ pode estar relacionada ao fato de que o uso e a ocupação do solo na região está quase que estritamente restrito a atividade agropecuária. Segundo Derísio (2000) maiores alterações referentes aos valores de $\mathrm{pH}$ são provocadas por despejos industriais, os quais no ponto de coleta em estudo não são observados.

Nota-se que, houve tendência da diminuição dos valores de $\mathrm{pH}$ com o aumento da vazão, contudo, a amplitude média dos valores observados foi pequena, entre 6,23 e 7,16, indicando valores aceitáveis segundo a Resolução CONAMA n. 357 (Brasil, 2005) a qual estipula valores de $\mathrm{pH}$ entre 6 e 9 para todas as classes de qualidade de água doce, ou seja, Classe 1 , que pressupõe os usos mais nobres até a Classe 4 que pressupõe os usos menos nobres. 


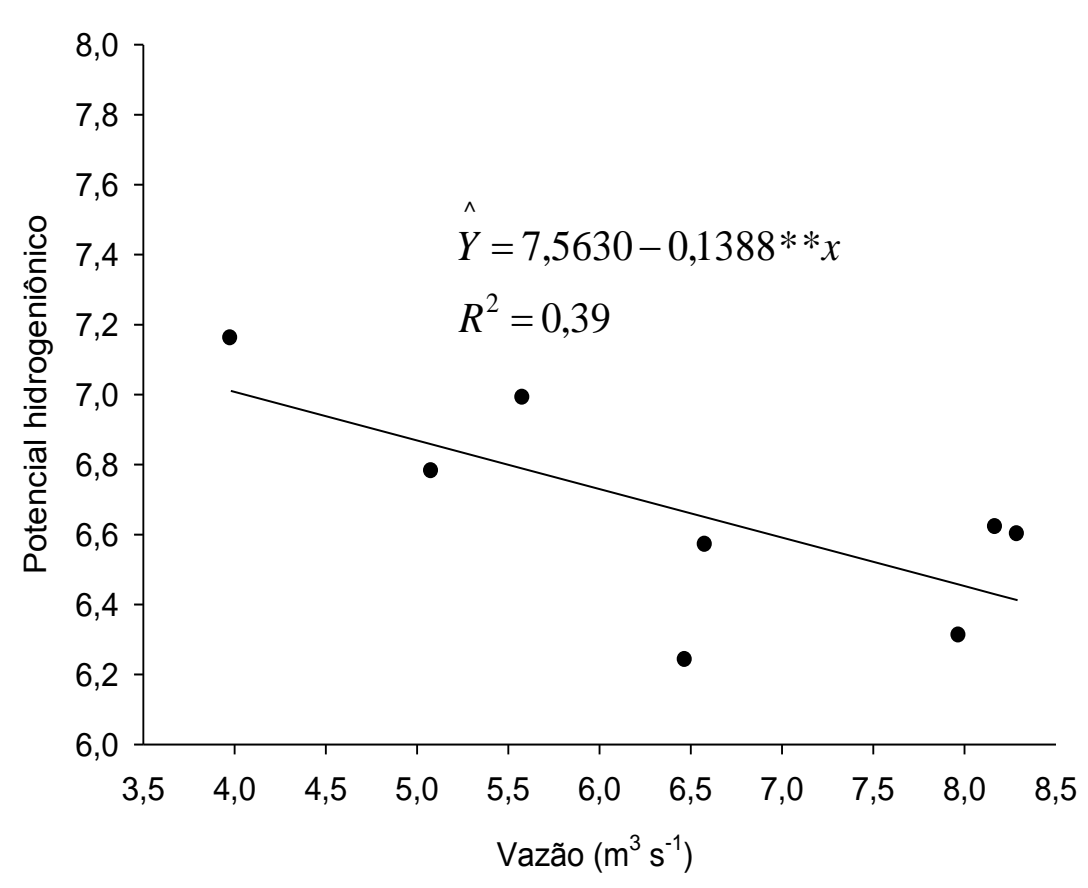

Figura 1. Valores médios observados e estimados do potencial hidrogeniônico $(\mathrm{pH})$ em função da vazão na seção transversal estudada do rio Catolé Grande. (**significativo a $1 \%$ pelo teste t).

A pequena variação dos valores de $\mathrm{pH}$ pode estar relacionada ao fato de que o uso e a ocupação do solo na região está quase que estritamente restrito a atividade agropecuária. Segundo Derísio (2000) maiores alterações referentes aos valores de pH são provocadas por despejos industriais, os quais no ponto de coleta em estudo não são observados.

Considerando todos os meses em estudo, nota-se que houve correlação negativa entre o pH e a vazão, - 0,62 (probabilidade de erro, $\mathrm{P}<0,01$ ), ou seja, há tendência de diminuição do $\mathrm{pH}$ com o aumento da vazão, assim como verificado na Figura 1. Vários autores (Alvarenga et al., 2012; Queiroz et al., 2013; Carvalho e Siqueira, 2010, entre outros) estudando outros cursos de água também verificaram a mesma tendência, porém todos corroboram com o fato de que é difícil estabelecer uma explicação imediata para o comportamento do pH apenas em função da vazão pois este é influenciado por inúmeros fatores, tais como sólidos, gases dissolvidos, dureza, alcalinidade, temperatura, fatores bióticos entre outros (Fritzons et al., 2003).

\subsection{Salinidade}

Na Figura 2 estão apresentados os resultados da salinidade observados e estimados por meio de equação ajustada em função da vazão no rio Catolé Grande. Todos os valores médios da salinidade se enquadraram abaixo do limite estabelecido pela Resolução CONAMA 357 de 2005, que fixa valores para salinidade até $0,5 \%$ para rios de Classe 2.

De acordo com a equação ajustada, houve tendência de aumento da concentração desta variável com o aumento da vazão, contudo a amplitude dos valores da salinidade foram baixas, variando de 0,04 a $0,08 \mathrm{ppm}$. Houve correlação positiva entre a salinidade e a vazão quando observado todo o período em estudo, 0,87 ( $<<0,01)$. Isso demonstra alta influência entre o aumento da vazão a concentração de sais nas águas do rio Catolé Grande. 


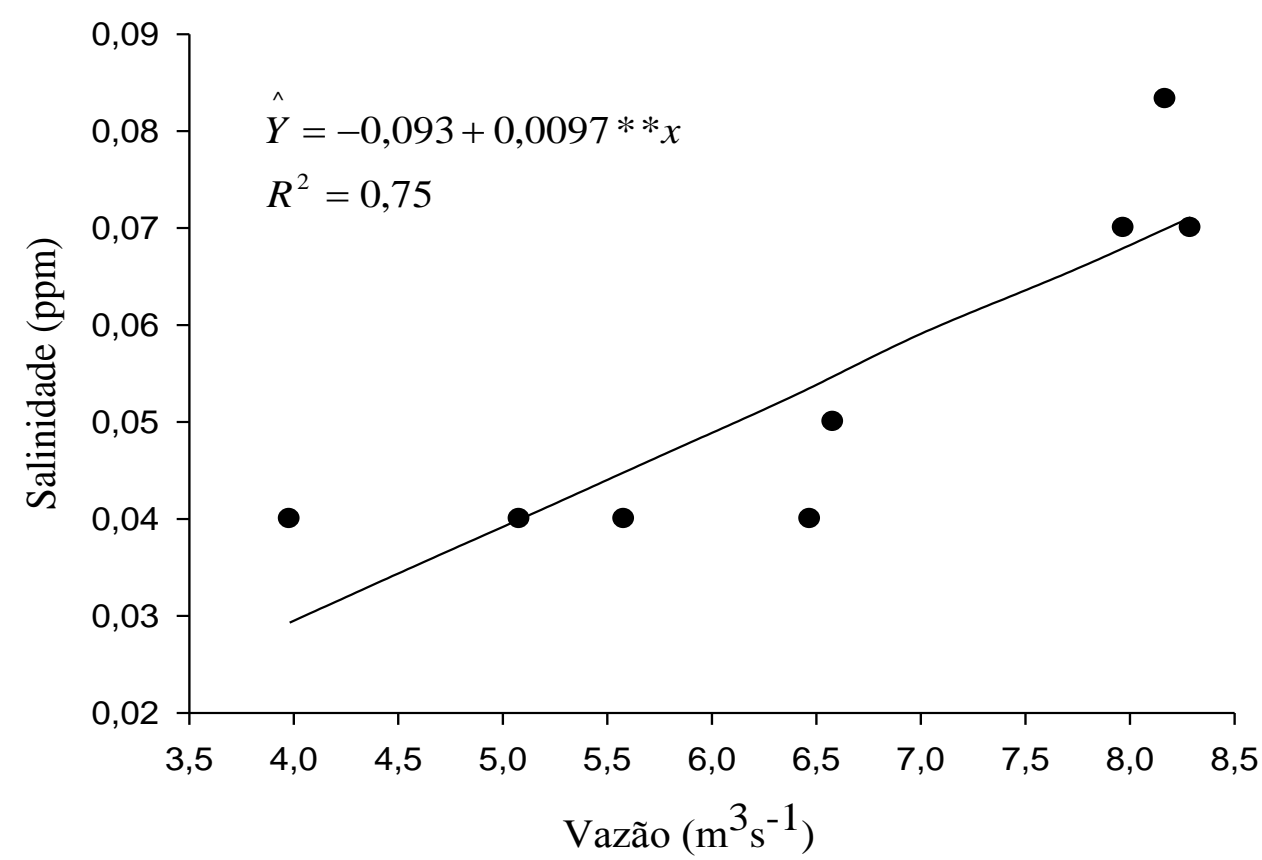

Figura 2. Valores médios observados e estimados da concentração da salinidade em função da vazão na seção transversal estudada do rio Catolé Grande. $(* *$ significativo a $1 \%$ pelo teste $\mathrm{t})$.

Barreto et al. (2009) monitoraram o comportamento da salinidade do rio Catolé Grande em uma seção próximo à captação de água do SAAE entre julho de 2008 a março de 2009. Os autores encontraram valores, em média, de 0,03 ppm para salinidade nos nove meses de coleta, corroborando com os resultados obtidos no presente estudo que apontam que a seção avaliada do rio possui baixa salinidade.

Oliveira et al. (2010) analisaram a bacia hidrográfica do rio Salitre, extremo norte da Bahia, entre os meses de maio a outubro de 2009, em 21 pontos de coleta de dados. Os autores destacaram que somente em quatro locais próximos às nascentes, os valores de salinidade permaneceram próximos ao limite estabelecido pela legislação em vigor; em dois pontos de coleta perto de áreas com formações calcárias a salinidade foi de 0,66 e 0,59 ppm, respectivamente. Os demais locais apresentaram maiores alterações das concentrações da salinidade, variando entre 0,96 a 2,8 ppm (água salobra). Os autores mencionaram que estas alterações das concentrações da salinidade sofreram influência de fatores como a geologia local e trechos que possuem contribuições de aquíferos calcários ou cristalinos que tendem a aumentar esta salinidade, o que não é o caso do rio Catolé Grande.

\subsection{Turbidez}

Na Figura 3 são apresentados os resultados da turbidez, observados e estimados por meio de equação ajustada em função das diferentes vazões no rio Catolé Grande, nos diferentes meses avaliados no ano de 2011.

Observa-se que a turbidez apresentou menor valor, 5,45 UNT, quando foi registrada a menor vazão $\left(3,98 \mathrm{~m}^{3} \mathrm{~s}^{-1}\right)$, ocorrendo também tendência do aumento da turbidez com o aumento da vazão. De acordo com os resultados obtidos, verificou-se que todas as amostras encontraram-se dentro dos padrões de qualidade de água estabelecidos na Resolução CONAMA n. ${ }^{\circ}$ 357/05, onde o valor de turbidez para rios de Classe 2, não deve exceder 100 UNT. 


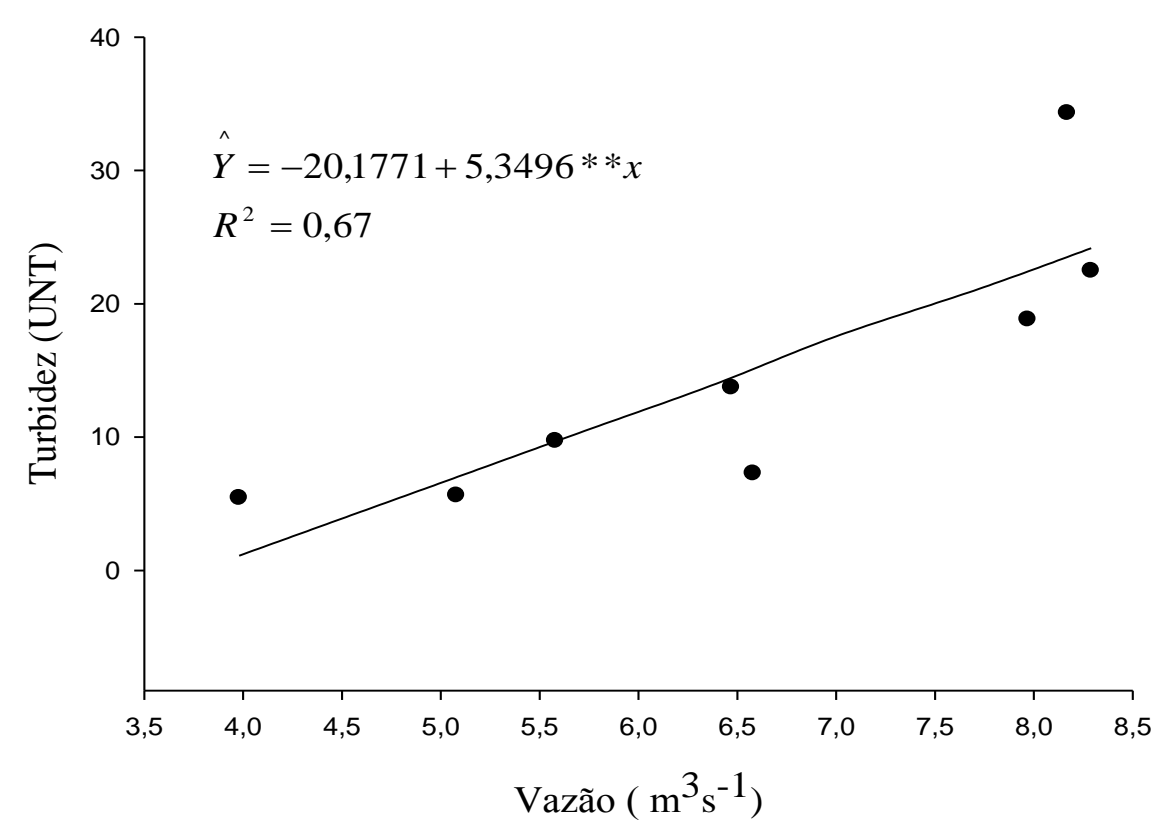

Figura 3. Valores médios observados e estimados da turbidez em função da vazão na seção transversal estudada do rio Catolé Grande, BA. $(* *$ significativo a $1 \%$ pelo teste $\mathrm{t})$.

Ficou constatada correlação positiva entre a turbidez e a vazão: 0,81 ( $\mathrm{P}<0,01)$, para todo o período em estudo. Desta forma, o aumento da vazão influenciou diretamente no aumento da turbidez. Segundo Santos et al. (2013), tal comportamento pode ser explicado devido ao fato de que durante as cheias, partículas de solo são carreadas para os rios, principalmente nessa bacia, em que a cobertura vegetal em sua grande parte é constituída de pastagens degradadas.

A turbidez utilizada isoladamente não é um parâmetro confiável para efeitos de contaminação, ela deve ser utilizada com outras análises que garantam maior confiabilidade aos resultados. É importante ressaltar que somente a turbidez, em sua origem natural, não traz inconvenientes sanitários diretos, porém pode reduzir a penetração da luz, prejudicando a fotossíntese (Imhoff, 1996).

Rocha et al. (2010) analisaram este mesmo ponto de coleta com amostragem de 0-20 cm de profundidade por integração vertical e constataram modificações nos valores de turbidez para os diferentes meses avaliados, variando aproximadamente entre 5 e 25 UNT. Os autores concluíram que esse fato pode ser atribuído às precipitações ocorridas, que contribuíram para o aumento desta variável, alocando assim ao rio maiores concentrações de partículas.

Barros et al. (2011) estudaram a variação da turbidez neste mesmo rio, no período compreendido entre maio e agosto de 2011. Os autores observaram que a turbidez variou com mais intensidade apenas na margem esquerda do rio, local de remanso onde existe presença significativa de plantas aquáticas, de grande quantidade de matéria orgânica e de sólidos em suspensão, quando comparado aos outros pontos de coleta.

Moura et al. (2009) verificaram no rio Cascavel, oeste do Paraná, que a turbidez apresentou resultados elevados no verão, chegando ao maior valor de 106,57 UNT, quando o índice pluviométrico foi maior, o que ocasionou revolvimento e transporte dos sedimentos presente no fundo do rio. 


\subsection{Sólidos totais dissolvidos (STD)}

Na Figura 4 são apresentados os resultados dos sólidos totais dissolvidos observados e estimados por meio de equação ajustada em função das diferentes vazões no rio Catolé Grande, nos meses avaliados no ano de 2011.

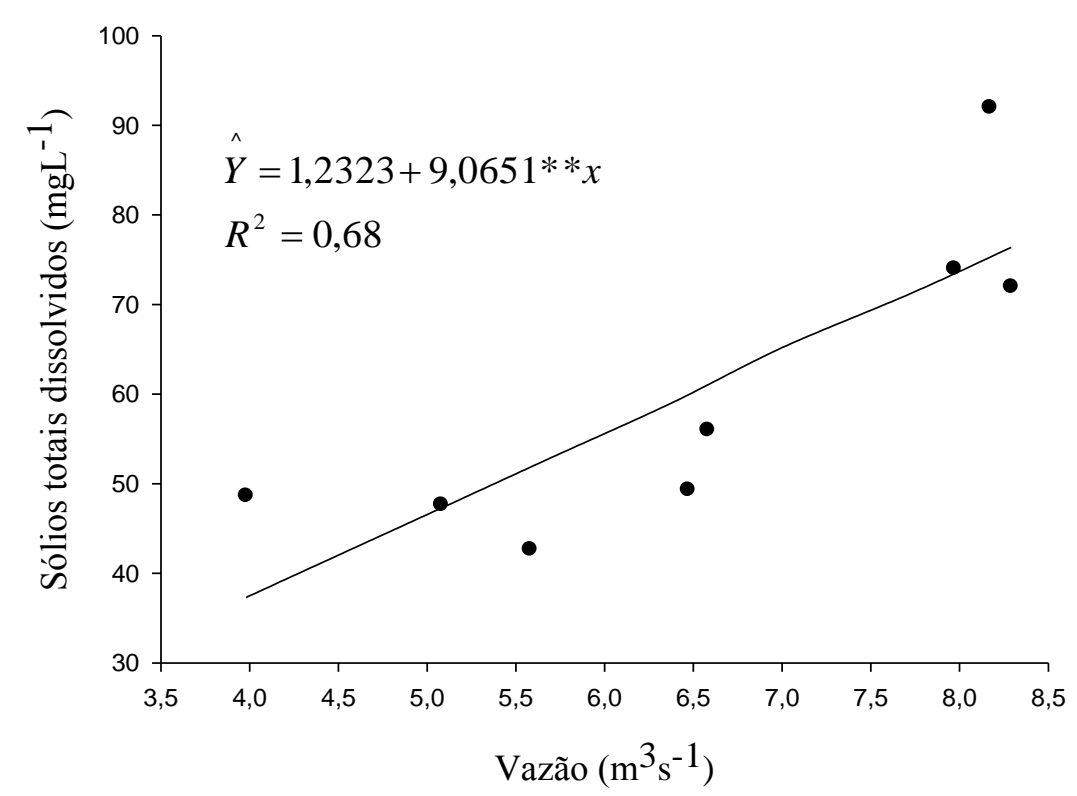

Figura 4. Valores médios observados e estimados dos sólidos totais dissolvidos em função da vazão na seção transversal estudada do rio Catolé Grande, BA. (**significativo a $1 \%$ pelo teste t).

Na Figura 4 pode-se observar o comportamento crescente na concentração dos STD com o aumento da vazão, semelhante ao que foi encontrado para a salinidade.

Os valores de sólidos totais dissolvidos variaram entre 42,66 e $92 \mathrm{mg} \mathrm{L}^{-1}$, muito abaixo do limite estabelecido pela Resolução CONAMA n. ${ }^{\circ} 357$, de 2005, a qual limita a concentração desta variável em $500 \mathrm{mg} \mathrm{L}^{-1}$ para rios de Classe 1 a 4 . Considerando todos os meses em estudo, houve correlação positiva entre o STD e a vazão de 0,82 ( $\mathrm{P}<0,01$ ).

Generoso et al. (2010) analisaram a quantidade de sólidos dissolvidos presentes na água do mesmo rio em estudo, em diferentes épocas e pontos distintos da seção transversal e verificaram que esta variável não apresentou grande variação entre os diferentes períodos avaliados, divergindo do presente estudo, que demonstra correlação positiva entre as duas variáveis.

Segundo Carvalho e Oliveira (2003), os sólidos dissolvidos na água indicam a presença de sais, ácidos minerais e outros contaminantes que se despejados no curso hídrico podem aumentar a demanda química e bioquímica de oxigênio nas águas, levando à depleção do oxigênio dissolvido no meio. Além disso, os sólidos totais dissolvidos podem demonstrar a carga de poluentes lançadas no curso de água.

Zanini et al. (2010) estudaram as águas da microbacia do córrego Rico em JaboticabalSP, entre setembro de 2007 e agosto de 2008, sendo realizadas coletas quinzenalmente em três pontos distintos. Os autores concluíram que os sólidos totais dissolvidos não apresentaram variação entre os pontos de montante à jusante e sim entre os períodos, destacando aumento no período de chuvas, corroborando assim com os resultados do presente estudo o qual constata maiores valores de sólidos totais dissolvidos em maiores níveis de vazão. 


\section{5..Fósforo total}

Na Figura 5 são apresentados os resultados do fósforo total observados e estimados por meio de equação ajustada em função das diferentes vazões no rio Catolé Grande, nos meses avaliados no ano de 2011.

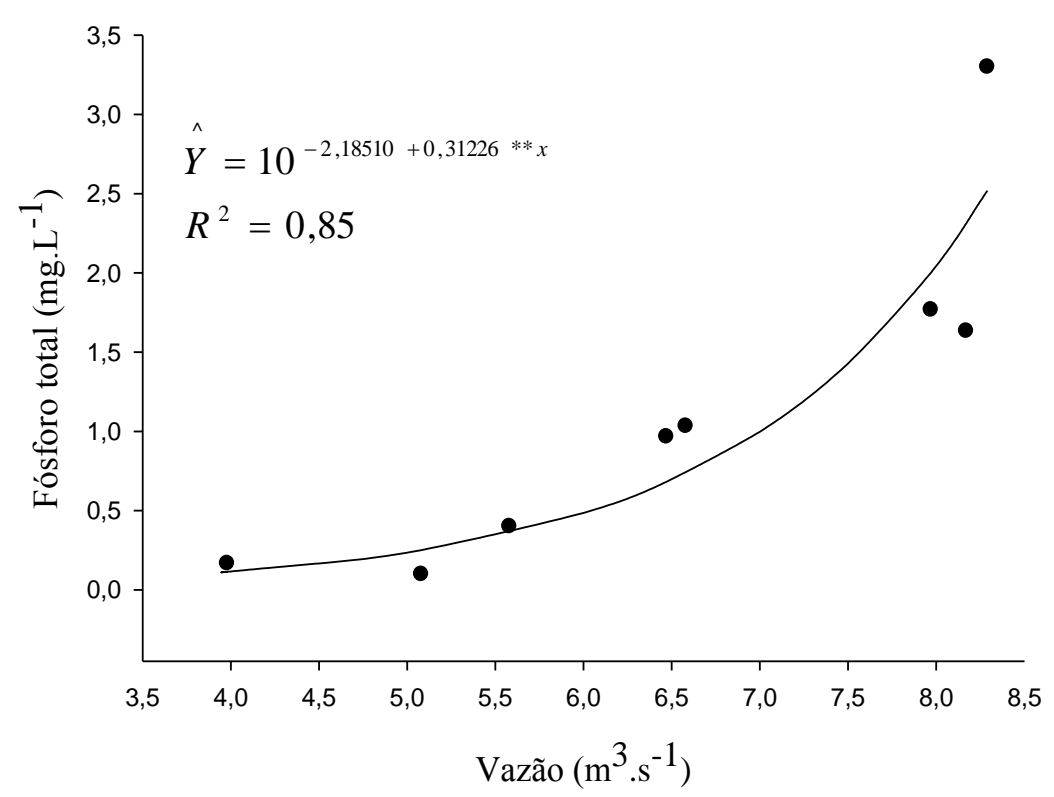

Figura 5. Valores médios observados e estimados do fósforo total em função da vazão na seção transversal estudada do rio Catolé Grande. (**significativo a $1 \%$ pelo teste $\mathrm{t}$ ).

De acordo com a figura verifica-se que o fósforo apresentou comportamento exponencial em função da vazão, sendo observada pequena variação crescente no valor desta variável até aproximadamente $6 \mathrm{~m}^{3} \mathrm{~s}^{-1}$, a partir desta vazão a concentração de fósforo total apresentou crescimento mais significativo. Este fato provavelmente ocorreu devido ao revolvimento do sedimento no leito do rio em função do aumento da vazão, deslocando o fósforo total decantado, influenciando assim no aumento da concentração desta variável na coluna de água. Segundo Koskivahala e Hartikainen (2001) e McDowell et al. (2001) em ambientes lóticos a dessorção do fósforo é facilitada pela ressuspensão dos sedimentos e pela turbulência da água.

Considerando todos os meses avaliados houve correlação positiva entre o fósforo total e a vazão, sendo esta de 0,62 ( $\mathrm{P}<0,01)$. Fia (2009) relata uma das causas do aumento da quantidade de fósforo total na água também pode ser devido a grande retirada deste nutriente do solo em épocas de chuva, o qual escoa para os corpos de água, sendo esta situação mais agravada em áreas agrícolas (Cunha et al., 2013).

Observando a média do período em estudo, a concentração do fósforo total foi de $1,17 \mathrm{mg} \mathrm{L}^{-1}$. Merece destaque a concentração média da coleta realizada no mês d maio, $3,3 \mathrm{mg} \mathrm{L}^{-1}$. Esses valores indicam que esta variável ficou acima dos valores estabelecidos pela resolução CONAMA 357/05 em relação a pior classe de qualidade de água (Classe 4).

\section{CONCLUSÃO}

Tendo por base os resultados obtidos e ponderando as condições em que o estudo foi realizado, conclui-se que:

A salinidade, a turbidez e os sólidos totais dissolvidos apresentaram correlações positivas em função das vazões analisadas, sendo observado comportamento linear crescente na 
concentração das variáveis com o aumento da vazão, em contrapartida os valores de $\mathrm{pH}$ apresentaram tendência de decréscimo com o aumento da vazão.

A concentração de fósforo total apresentou comportamento exponencial positivo em função da vazão, sendo a provável causa desse comportamento o revolvimento de sedimentos do leito do rio.

Os valores de $\mathrm{pH}$ estão dentro da faixa de valores para águas de Classes 1 a 4 estabelecidos pela resolução CONAMA (6 a 9), assim como as concentrações de sólidos totais dissolvidos se situam muito abaixo do limite máximo para estas classes $\left(500 \mathrm{mg} \mathrm{L}^{-1}\right)$, ao contrário, os valores médios de fósforo total, estão acima do estabelecido para águas doces Classe 4.

\section{REFERÊNCIAS}

ALVARENGA, L. A.; MARTINS, M. P. P; CUARTAS, L. A.; PENTEADO, V. A.; ANDRADE A. Estudo da qualidade e quantidade da água em microbacia, afluente do rio Paraíba do Sul - São Paulo, após ações de preservação ambiental. Revista Ambiente \& Água, Taubaté, v. 7, n. 3, 2012. http://dx.doi.org/10.4136/ambi.agua.987

AMERICAN PUBLICA HEALTH ASSOCIATION - APHA; AMERICAN WATER WORKS ASSOCIATION - AWWA; WATER ENVIRONMENT FEDERATION WEF. Standard methods for the examination of water and wastewater. Washington, DC, 2005.

BARRETO, L. V.; ROCHA, F. A.; OLIVEIRA, M. S. C. Monitoramento da qualidade da água na microbacia hidrográfica do rio Catolé, em Itapetinga-BA. Enciclopédia Biosfera, Goiânia, v. 5, n. 8, 2009.

BARROS, F. M.; ROCHA, F. A.; FRAGA, M. S.; GENEROSO, T. N.; MELO, A. R. B. Variação da turbidez em pontos distintos de um perfil transversal do rio Catolé-BA, sob diferentes níveis de vazão. Enciclopédia Biosfera, Goiânia, v. 7, n. 12, 2011.

BRAGA, B.; HESPANHOL, I.; CONEJO, J. G. L.; MIERZWA, J. C.; BARROS, M. T. L.; SPENCER, M. et al. Introdução à engenharia ambiental. São Paulo: Prentice Hall, 2005.

BRASIL. Ministério do Meio Ambiente. Conselho Nacional do Meio Ambiente - CONAMA. Resolução no 357 de 17 de março de 2005. Disponível em: <http://www.mma.gov.br /port/conama/res/res05/res35705.pdf>. Acesso em: 22 de agosto de 2011.

CARVAlho, R. A; OliveirA, M. C. V. Princípios Básicos de Saneamento do Meio. São

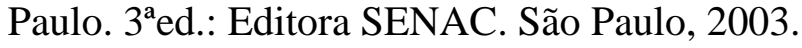

CARVALHO, G. L.; SIQUEIRA, E. Q. Qualidade da água do rio Meia Ponte no perímetro urbano do município de Goiânia-Goiás. Revista Eletrônica de Engenharia Civil, Goiás, v. 1, n. 1, 2010.

CUNHA, R. W.; GARCIA JUNIOR, M. D. N.; ALBERTONI, E. F.; PALMA-SILVA, C. Qualidade de água de uma lagoa rasa em meio rural no sul do Brasil. Revista Brasileira de Engenharia Agrícola e Ambiental, Campina Grande, v. 17, n. 7, 2013. http://dx.doi.org/10.1590/S1415-43662013000700012

DERISIO, J. C. Introdução ao controle da poluição ambiental. São Paulo: Signus, 2000. 
FIA, R.; MATOS, A. T.; CORADI, P. C.; PEREIRA-RAMIREZ, O. Estado trófico da água na bacia hidrográfica da Lagoa Mirim, RS, Brasil. Revista Ambiente \& Água, Taubaté, v. 4, n. 1, 2009. http://dx.doi.org/10.4136/ambi.agua.78

FRITZSONS, E.; HINDI, E. C.; MANTOVANI, L. E.RIZZI, N. E. As alterações da qualidade da água do rio Capivari com o deflúvio: um instrumento de diagnóstico de qualidade ambiental. Engenharia Sanitária e Ambiental, Rio de Janeiro, v. 8, n. 4, 2003.

GENEROSO, T. N.; FRAGA, M. S.; BARROS, F. M.; TAGLIAFERRI, C.; ROSA, R. C. C. Influência do local de amostragem nos valores de variáveis de qualidade de água em uma seção transversal do rio Catolé-BA. Enciclopédia Biosfera, Goiânia, v. 6, n. 11, 2010 .

HADDAD, E. A.; MAGALHAES JUNIOR, A. P. Influência antrópica na qualidade da água da bacia hidrográfica do rio são Miguel, Carste do alto São Francisco, Minas Gerais. Geosul, Florianópolis, v. 25, n. 49, 2010.

IMHOFF, K. R. Manual de tratamento de águas residuárias. Tradução de Max Lothar Hess. São Paulo: Edgard Blucher, 1996.

KOSKI-VAHALA, J.; HARTIKAINEN, H. Assessment of the risk of phosphorus loading due to resuspended sediment. Journal of Environmental Quality, Madison, v. 30, p. 960-966, 2001. http://dx.doi.org/10.2134/jeq2001.303960x

McDOWELl, R. W.; SHARPLEY, A. N.; CONDRON, L. M.; HAYGORTH, P. M.; BROOKES, P. C. Processes controlling soil phosphorus release to runoff and implications for agricultural management. Nutrient Cycling in Agroecosystems, v. 59, p. 269-284, 2001. http://dx.doi.org/10.1023/A:1014419206761

MOURA, A. C.; ASSUMPÇÃO, R. A. B.; BUSCHOFF, J. Monitoramento físico-químico e microbiológico da água do rio cascavel durante o período de 2003 a 2006. Arquivos do Instituto Biológico, São Paulo, v. 76, n. 1, 2009.

NETO, M. L. F.; FERREIRA, A. P. Perspectivas da Sustentabilidade Ambiental Diante da Contaminação Química da Água: Desafios Normativos. Revista de Gestão Integrada em Saúde do Trabalho e Meio Ambiente, v. 2, n. 4, 2007.

PRUSKI, F. F.; SILVA, D. D. da; KOETZ, M. Estudo de vazão em cursos d'água. Viçosa: AEAGRI, 2006. 151 p. (Caderno Didático, 43)

QUEIROZ M. M. F.; DANTAS, E. F.; SILVA, A. L. Qualidade e quantidade da água do rio Piancó, tributário do rio Piranhas Açu na região nordeste. Revista Verde de Agroecologia e Desenvolvimento Sustentável, v. 8, n. 2, 2013.

ROCHA, F. A.; OLIVEIRA, M. S. C.; MELO, A. R. B.; BARROS, F. M.; BARRETO, L. V. Variáveis de qualidade de água influenciadas pelo tipo e época de amostragem, no rio Catolé-BA. Enciclopédia Biosfera, Goiânia, v. 6, n. 11, 2010.

SANTOS, Q. R; FRAGA, M. S.; ULIANA, E. M; REIS, A. S; BARROS, F. M. Monitoramento da qualidade da água em uma seção transversal do rio Catolé, Itapetinga-BA. Enciclopédia Biosfera, Goiânia, v.9, n.16, 2013. 
ZANINI, H. L. H. T.; AMARAL, L. A.; ZANINI, J. R.; TAVARES, L. H. S. Caracterização da água da microbacia do córrego Rico avaliada pelo índice de qualidade de água e de estado trófico. Engenharia Agrícola, Jaboticabal, v. 30, n. 4, 2010. http://dx.doi.org/10.1590/S0100-69162010000400017 